\title{
DISTRIBUIÇÃO GEOGRÁFICA E DIFUSÃO ESPACIAL DO \\ CORONAVÍRUS/COVID-19 NO BURQUINA FASSO (ÁFRICA OCIDENTAL)
}

\author{
Geographic distribution and spatial diffusion of Coronavirus / COVID-19 \\ in Burkina Faso (Western Africa) \\ Distribución geográfica y difusión espacial de Coronavirus / COVID-19 \\ en Burkina Faso (África occidental)
Distribution géographique et diffusion spatiale du Coronavirus / COVID-19 au Burkina Faso (Afrique de l'Ouest)

\author{
Abdoul Azise Sodoré \\ Doutor em Geografia \\ Expert em Desenvolvimento Territorial Sustentável \\ Laboratoire d'Études et Recherche sur les Milieux et Territoires (LERMIT) \\ Universidade Joseph KI-ZERBO, Ouagadougou, Burkina Fasso \\ azizsodore@yahoo.fr \\ Frédéric Monié \\ Doutor em Geografia \\ Grupo de Estudos Espaços e sociedades na África subsaariana \\ Departamento de Geografia e Programa de Pós-Graduação em Geografia (PPGG) \\ Universidade Federal do Rio de Janeiro, Rio de Janeiro, Brasil \\ frederic.rj@gmail.com
}

Léonard Pegwendé Pouya

Especialista em Sistemas de Informação Geográfica / Sensoriamento remoto

Departamento de Geografia

Laboratoire Études et Recherche sur les Milieux et Territoires (LERMIT)

Universidade Joseph KI-ZERBO, Ouagadougou, Burkina Fasso

lpp.leo86@gmail.com

Artigo enviado para publicação em 30/04/2020 e aceito em 01/05/2020

DOI: $10.12957 /$ tamoios.2020.50604

\section{Resumo}

A trajetória da pandemia de Coronavírus/COVID-19 na África subsaariana e em Burquina Fasso seguirá provavelmente o padrão temporal e espacial observado internacionalmente: uma fase contágio comunitário seguirá, com intensidade e impactos variáveis, a importação do vírus do exterior. Neste cenário, Burquina Fasso já se singulariza pela elevada taxa de contaminação da população pelo Coronavírus e de letalidade do COVID-19. O país se diferencia também pela complexidade dos processos de difusão espacial da pandemia que articulam lógicas reticulares e territoriais de contágio em diversas escalas geográficas. Apesar de suas limitações intrínsecas, a teoria da difusão espacial fornece recursos metodológicos que, a condição de incorporar varáveis analíticas adaptadas à compreensão do mundo global contemporâneo, consideramos muito relevantes para o estudo da natureza da cadeia de contágio e dos mecanismos de disseminação do vírus na sociedade e no espaço.

Palavras chave: Coronavírus/COVID-19; difusão espacial; África subsaariana; Burquina Fasso 


\begin{abstract}
Resumen
La trayectoria de la pandemia de Coronavirus / COVID-19 en África subsahariana y Burkina Faso probablemente seguirá el patrón temporal y espacial observado internacionalmente: una fase de contagio comunitario seguirá, con intensidad e impactos variables, la importación del virus desde el extranjero. En este escenario, Burkina Faso ya se distingue por la alta tasa de contaminación de la población por el coronavirus y la letalidad de COVID-19. El país también se diferencia por la complejidad de los procesos de difusión espacial de la pandemia que articulan lógicas reticulares y territoriales de contagio en diferentes escalas geográficas. A pesar de sus limitaciones intrínsecas, la teoría de la difusión espacial proporciona recursos metodológicos que, con la condición de que incorpore variables analíticas adaptadas a la comprensión del mundo global contemporáneo, consideramos muy relevante para el estudio de la naturaleza de la cadena de contagio y los mecanismos de propagación del virus en el sociedad y espacio.
\end{abstract}

Palabras clave: Coronavirus / COVID-19; difusión espacial; África subsahariana; Burkina Faso

\begin{abstract}
The trajectory of the Coronavirus / COVID-19 pandemic in sub-Saharan Africa and Burkina Faso will probably follow the temporal and spatial pattern observed internationally: a community contagion phase will follow, with varying intensity and impacts, the import of the virus from abroad. In this scenario, Burkina Faso is already distinguished by the high rate of contamination of the population by the Coronavirus and the lethality of COVID-19. The country is also differentiated by the complexity of the processes of spatial diffusion of the pandemic that articulate reticular and territorial logics of contagion in different geographical scales. Despite its intrinsic limitations, the theory of spatial diffusion provides methodological resources that, on condition that it incorporates analytical variables adapted to the understanding of the contemporary global world, we consider very relevant to the study of the nature of the contagion chain and the mechanisms of virus spread in the society and space.
\end{abstract}

Keywords: Coronavirus / COVID-19; spatial diffusion; Sub-Saharan Africa; Burkina Faso.

\title{
Résumé
}

La trajectoire de la pandémie de Coronavirus / COVID-19 en Afrique subsaharienne et au Burkina Faso suivra probablement le schéma temporel et spatial observé à l'échelle internationale: une phase de contagion communautaire suivra, avec une intensité et des impacts variables, l'importation du virus de l'étranger. Dans ce scénario, le Burkina Faso se distingue déjà par le taux élevé de contamination de la population par le coronavirus et la létalité du COVID-19. Le pays se différencie également par la complexité des processus de diffusion spatiale de la pandémie qui articulent les logiques réticulaires et territoriales de contagion à différentes échelles géographiques. Malgré ses limites intrinsèques, la théorie de la diffusion spatiale fournit des ressources méthodologiques que, à condition qu'elle intègre des variables analytiques adaptées à la compréhension du monde global contemporain, nous considérons comme très pertinentes pour l'étude de la nature de la chaîne de contagion et des mécanismes de propagation du virus dans la société et espace.

Mots-clés: Coronavirus / COVID-19; diffusion spatiale; Afrique sub-saharienne; Burkina Faso 


\section{Introdução}

$\mathrm{Na}$ África subsaariana, a trajetória da pandemia de Coronavírus/COVID-19 seguirá provavelmente o padrão temporal e espacial observado internacionalmente desde o mês de janeiro de 2020. Após a importação dos primeiros casos de contaminação, via transporte aéreo, ingressamos na fase do contágio comunitário que potencializa o crescimento exponencial do número de pessoas contaminadas. Numa região do mundo extremamente diversa, os impactos sanitários são de difícil previsão se consideramos a diversidade das formações socioespaciais, o nível diferenciado de eficiência das políticas de contenção promulgadas pelos governos nacionais e locais, a heterogeneidade de sistemas públicos de saúde, cuja capacidade de resposta oscila em função do nível de desenvolvimento, das condições sociais dos habitantes, da densidade populacional, da qualidade da gestão das unidades etc. Em Burquina Fasso, país localizado na sub-região do Sahel na África ocidental, as taxas de contaminação pelo Coronavírus e de letalidade do COVD-19 são muito superiores à média oficialmente registrada pela Organização Mundial da Saúde (OMS) a partir dos dados fornecidos pelas autoridades sanitárias nacionais. Esses dados são, como no resto do mundo, tributários da escala das operações de testagem da população, num contexto de escassez e distribuição extremamente desigual dos testes de detecção. O caso de Burquina Fasso nos parece também relevante se consideramos a complexidade dos processos de difusão espacial do Coronavírus que articulam lógicas reticulares e territoriais de contágio em diversas escalas geográficas. As métricas da propagação evoluem também em função da heterogeneidade do espaço geográfico.

A análise sintética da dimensão geográfica da evolução da pandemia em Burquina Fasso aqui apresentada é fruto de uma parceria entre geógrafos da Universidade Joseph Ki-Zerbo de Ouagadougou e da Universidade Federal do Rio de Janeiro. Acreditamos que, apesar de limitações intrínsecas, a teoria da difusão espacial elaborada na década de 1950 por Torsten Hägerstrand e seus seguidores, propicia recursos metodológicos e analíticos relevantes para a apreensão da natureza da cadeia de contágio e dos mecanismos de disseminação do vírus na sociedade e no espaço do país.

\section{Os processos de difusão espacial}

No final do século XIX, etnólogos alemães, ingleses e norte-americanos adotaram a noção de difusão para destacar a relevância de fenômenos de difusão cultural no contexto intelectual contemporâneo do auge do imperialismo europeu, caracterizado pela afirmação da superioridade da cultura e da civilização ocidentais. $O$ difusionismo legitimava, então, a missão civilizadora da Europa ocidental nos territórios recém colonizados (MASCARENHAS, 2000). Apesar de Ratzel (Antropogeografia) e alguns seguidores (Ankermann, Graebner) terem criado, no mesmo período, um método difusionista de análise, os geógrafos, ao contrário dos etnólogos interessados pela circulação de línguas, ideias ou práticas culturais, permanecerem globalmente exteriores aos debates da época (RAFFESTIN, 1994). Carl Sauer, fundador da Escola de Berkeley, se singularizou adotando os princípios de difusão e dispersão na construção da "morfologia da paisagem" que adere ao postulado difusionista dos etnólogos sobre a superioridade de determinadas regiões de cultura como vocação civilizadora (MASCARENHAS, 2000)

Foi somente no início da década de 1950, que a problemática da difusão ressurgiu na Geografia, com a publicação de uma série de artigos pelo geógrafo sueco Torsten Hägerstrand. O professor da Universidade de Lund propõe então uma abordagem 
nomotética de fenômenos de difusão de inovações, evidenciando a ocorrência de processos e de regularidades temporais e espaciais (HÄGERSTRAND, 1952). Segundo Gilberto Mascarenhas (2000) "na teoria difusionista moderna, a modernização" substitui o efeito "civilização" e a suposta superioridade econômica-tecnológica faz excluir a tese da superioridade racial". Num período marcado pela crise da corrente geográfica ideográfica e pela consolidação da geografia teorética, as regularidades empiricamente observadas estimulam a elaboração de modelos com elevado nível de abstração. A investigação do papel destas regularidades na estruturação do espaço geográfico começa a alimentar pesquisas em análise espacial (SAINT-JULIEN, S/D).

O principal modelo empírico-descritivo de Hägerstrand (1952) distingue 4 fases principais: 1) a primeira é caracterizada por um importante contraste entre o foco de inovação e espaços distantes. Neste momento, distâncias geográfica e/ou sociocultural determinam o ritmo e a intensidade da difusão; 2) a segunda fase corresponde ao processo de difusão, segundo uma lógica centro/periferia que permite alcançar espaços distantes; 3) a terceira etapa é marcada por uma diminuição das disparidades; e 4) a quarta fase é a da saturação, quando "o aumento assintomático da difusão tende para seu patamar máximo" (RAFFESTIN, 1994, p.190).

Segundo Torsten Hägerstrand (1952), para que a difusão espacial não seja assimilada a um simples movimento no espaço, algumas condições são necessárias: 1) a inovação deve surgir num lugar apto ao deslocamento; 2) o lugar deve ter capacidade de tornar-se um foco de emissão; 3) a existência de um meio de recepção favorável à uma propagação rápida; 4) uma força de alastramento satisfatório e um tempo de propagação suficientemente longo para que o processo de difusão não seja interrompido.

O geógrafo sueco aponta que os processos de difusão espacial ocorrem a partir de determinado lugar segundo ondas de continuidades (HÄGERSTRAND, 1952). As ondas de continuidades apresentam uma forte dimensão zonal. $\mathrm{O}$ chamado efeito de vizinhança é fundamental numa escala de propagação local ou regional. Para completar o raciocínio de Hägerstrand, conceitos e noções geográficos se revelam complementares para analisar o fenômeno de difusão zonal: lugar central (CHRISTALLER, 1966), co-presença (LÉVY, 2001), território-zona (VELTZ, 1999; HAESBAERT, 2020), efeito túnel (OFFNER, 1993) etc.

Num segundo momento, sendo sensível à estrutura hierárquica dos sistemas, a intensidade da difusão costuma acompanhar a hierarquia urbana segundo uma lógica decrescente. Por essa razão, quando maior o centro inicial de propagação, maior será $a$ priori, sua força de impulso e a probabilidade da difusão do fenômeno através do sistema (SAINT-JULIEN, S/D). Numa rede de trocas materiais e imateriais contemporânea, a inovação pode circular entre um ponto $\mathrm{O}$ de origem e um ponto $\mathrm{D}$ de destino sem interação com os espaços intermediários atravessados. Estamos diante de um fenômeno de efeito túnel que tem hoje grande relevância nos processos de difusão e na elaboração de políticas de gestão do território (OFFNER, 1993). Na atualidade, o transporte aéreo potencializa, por exemplo, fenômenos de difusão muito mais complexos na perspectiva de um espaço-tempo comprimido pela densidade, eficiência e sofisticação da malha aeroportuária mundial. Em 2020, a circulação mundial do Coronavírus ilustra uma lógica de difusão rápida e intensa entre lugares hiperconectados ao espaço global de fluxos (CASTELLS, 1999) como Wuhan, Milão, Madri, Londres ou Nova Iorque (MONIÉ, 2020). Espaços relativamente contíguos à essas metrópoles internacionais (centro da China, regiões central e meridional da Itália etc.) apresentam, assim, níveis de contaminação muito inferiores.

Convém ressaltar que o processo de difusão espacial de um fenômeno, material ou imaterial, se depara com efeitos de barreira (físicos, culturais, técnicos, geopolíticos 
etc.) suscetíveis de limitar ou frear as interações espaciais. No caso da pandemia de Coronavírus/COVID-19, as medidas de contenção territorial adotadas mundialmente constituem, por exemplo, um efeito de barreira frente aos riscos de contágio.

A teoria da difusão e os modelos prospectivos elaborados pela geografia teorética das décadas de 1950 e 1960 apresentam diversas limitações metodológicas. As principais críticas da Geografia destacaram que os estudos difusionistas da new geography ignoravam sistematicamente a complexidade da dinâmica social do espaço geográfico (HARVEY, 1973) e as características próprias a cada formação socioespacial (SANTOS, 1978). Desde então, a teoria foi globalmente abandonada pela ciência geográfica, com exceção da Geografia da saúde que pesquisa a difusão de doenças e processos de contágio epidemiológicos.

A atual crise pandêmica legitima, no entanto, o recurso à métodos de análise da teoria da difusão. As características e as complexidades dos espaços geográficos são hoje muito mais conhecidas e valorizadas graças aos aportes teóricos, metodológicos e empíricos de diversas correntes geográficas. A geografia crítica possibilita, por exemplo, novas abordagens, integrando problemáticas como as desigualdades sociais, a segregação socioespacial ou a precarização do trabalho pouco qualificado, fornecendo elementos pertinentes de compreensão da difusão da pandemia em diversas escalas. O exemplo dos Estados Unidos, onde a contaminação de minorias étnicas pelo Coronavírus/COVID-19 é desproporcional em relação à sua representação estatística no total da população, nos lembra que, em determinados contextos, a inclusão da variável étnico-racial é, também, relevante para a análise de processos de difusão de epidemias. O critério de gênero pode, por sua parte, conferir um víeis intersecional às análises.

O estudo de processos de difusão espacial deve também incorporar elementos analíticos de tendências e fenômenos ilustrativos das grandes mudanças contemporâneas, em particular relacionadas à globalização da economia e do comércio. A compressão do espaço tempo (HARVEY, 1989) é, assim, uma variável de análise particularmente relevante no estudo de processos de difusão espacial no contexto contemporâneo. Para isso, devem ser destacados os progressos registrados na operação e gestão dos sistemas de comunicação e transportes que diminuem as fricções do tempo e da distância na circulação de pessoas, bens e informações, transformando as métricas da mobilidade e modificando os processos de difusão (LÉVY, 2001). A formação de um espaço global de fluxos (CASTELLS, 1999) no seio do qual pessoas, mercadorias e informações circulam em volumes, distancias e velocidades crescentes representa um fator crítico da aceleração dos ritmos dos processos de difusão espacial.

Consideramos que, conforme o exemplifica o caso do Coronavírus/COVID-19 em Burquina Fasso, o recurso à noção de difusão espacial e à alguns dos métodos de análise propostos por Hägerstrand e seus seguidores, são, portanto, pertinentes para apreender a geografia do contágio, a condição de integrar elementos de reflexão e debates do tempo presente.

\section{A pandemia de Coronavírus/COVID-19 no Burquina Fasso: situação sanitária}

Os primeiros casos de contaminação pelo Coronavírus na África subsaariana foram oficialmente notificados no final do mês de fevereiro (Lagos, Nigéria) e início do mês de março de 2020 (Dacar, Senegal), ou seja, dois meses depois do primeiro registro de uma pneumonia atípica num hospital da cidade chinesa de Wuhan. O descompasso temporal em relação ao foco inicial de difusão da pandemia e aos principais epicentros regionais é a consequência da inserção periférica do continente nos circuitos produtivos, comerciais e logísticos da globalização (MONIÉ, 2020). Desde então, o ritmo de difusão 
do Coronavírus entre as sociedades subsaarianas é relativamente lento, sobretudo quando comparado à dinâmicas observadas em outras regiões do mundo (Europa ocidental, América do Norte). Essa particularidade pode ser relacionada ao fato que estamos ainda nos primórdios da propagação comunitária do vírus. Podemos, também, nos questionar a respeito do possível êxito de medidas tomadas pelos governos imediatamente depois da confirmação dos primeiros casos de contaminação. Convém, também, asseverar que a escassez de testes de detecção e a precariedade do levantamento de dados em áreas periféricas e/ou geopoliticamente conflagradas geram um descompasso entre a informação dos registros oficiais e o real contexto sanitário do momento (MONIÉ, 2020; ONYIEGO, 2020).

Tabela 1

Coronavírus/COVID-19 em Burquina Fasso, na África e no Mundo (dados 26/04)

\begin{tabular}{|l|c|c|c|}
\hline & contaminados & $\begin{array}{c}\text { contaminados } \\
\text { /M. hab. }\end{array}$ & $\begin{array}{c}\text { mortos por } \\
\text { COVID-19 }\end{array}$ \\
\hline Burquina Fasso & 632 & 28,6 & 42 \\
\hline África* & 19.550 & 18,36 & 835 \\
\hline Mundo & 2.850 .387 & 366,0 & 203.622 \\
\hline
\end{tabular}

Fonte: OMS

*Região África da OMS: continente africano menos Marrocos, Líbia, Egito, Tunísia, Sudão, Djibuti, Somália

Na escala da África ocidental, observamos importantes disparidades na situação sanitária de alguns países vizinhos de Burquina Fasso (tabela 2). As desigualdades intrarregionais se expressam de diferentes maneiras. A taxa de contaminação é a priori mais elevada em Gana, Costa do Marfim e Senegal, países que aplicam mais testes de detecção graças aos recursos financeiros que lhe propicia um nível de desenvolvimento superior à média regional. Ao contrário, os mesmos países apresentam uma taxa de letalidade muito inferior à registrada entre os vizinhos do Sahel (Burquina Fasso, Mali e Níger) que figuram entre os mais pobres da África e do mundo.

Tabela 2

Coronavírus/COVID-19 em Burquina Fasso e em países vizinhos

\begin{tabular}{|l|c|c|c|c|}
\hline \multicolumn{1}{|c|}{ País } & $\begin{array}{c}\text { casos } \\
\text { Covid-19 }\end{array}$ & $\begin{array}{c}\text { taxa de } \\
\text { contaminação } \\
\text { (por 100.000 h) }\end{array}$ & óbitos & $\begin{array}{c}\text { taxa de } \\
\text { letalidade } \\
(\%)\end{array}$ \\
\hline Burquina Fasso & 632 & 3,06 & 42 & 6,65 \\
\hline Mali & 389 & 1,90 & 23 & 5,91 \\
\hline Níger & 696 & 1,91 & 29 & 4,71 \\
\hline Senegal & 671 & 3,84 & 09 & 1,34 \\
\hline C. do Marfim & 1.150 & 4,49 & 14 & 1,22 \\
\hline Gana & 1.550 & 5,08 & 11 & 0,71 \\
\hline
\end{tabular}

Fonte: OMS. WCO dashboard

Burquina Fasso é um país da África ocidental, de 21 milhões de habitantes em grande maioria jovens, localizado no coração do Sahel e do delta interior do rio Níger, fazendo fronteira com Mali, Níger, Costa do Marfim, Gana, Togo e Benim. A maioria da população vive em áreas rurais, onde a agricultura emprega ainda cerca de $90 \%$ da população economicamente ativa (MAHRH, 2014). A baixa densidade demográfica e o baixo nível de produtividade das atividades agrícolas (30,3\% do PIB em 2015) 
(BURKINA FASSO, s/d) desenham um quadro sanitário preocupante nas regiões rurais mais pobres do país, onde as unidades do sistema de saúde são mais escassas e precárias e a população em situação de insegurança alimentar é mais vulnerável. Por sua parte, a mineração aurífera tem se desenvolvido significativamente nos últimos anos, ao ponto que o ouro se tornou o maior produto de exportação do país na frente do algodão. A multiplicação de sítios extrativistas em áreas periféricas do país representa um fator de risco suplementar.

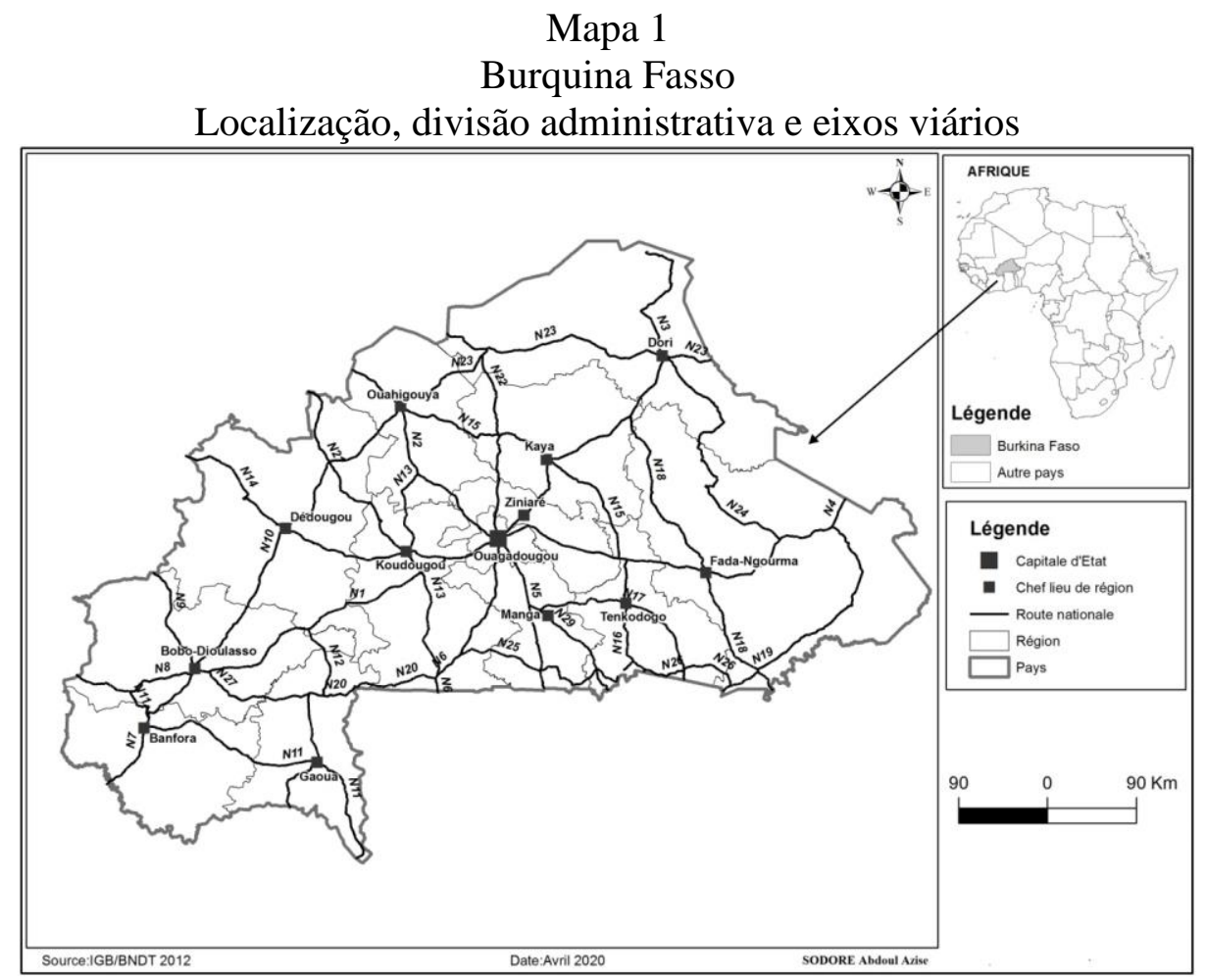

Segundo dados da Organização Mundial da Saúde (OMS), Burquina Fasso se singulariza por apresentar a maior taxa de letalidade do COVID-19 $(6,65 \%)$ entre os países vizinhos e uma das mais altas do continente africano (WCO dashboard, 27/04/2020). Algumas variáveis ajudam a apreender as causas do fenômeno: IDH baixo (0,434; posição 182 no ranking mundial do desenvolvimento humano em 2018); insegurança alimentar e sanitária estrutural em algumas regiões; precariedade do sistema de saúde; desigualdades regionais; porosidade das fronteiras; instabilidade geopolítica etc. Esse elevado nível de letalidade da doença constituiu um motivo de preocupação para a sociedade, antes mesmo do crescimento mais vigoroso do número de pessoas contaminadas mediante o contágio comunitário.

\section{Autoridades e sociedade de Burquina Fasso diante da pandemia de Coronavírus/COVID-19}

A gestão da pandemia é globalmente tributária da qualidade do sistema público de saúde, da eficiência das medidas tomadas pelas autoridades e, também, da pressão exercida pela sociedade civil, cuja mobilização pode influenciar a política das autoridades locais e nacionais. 
Como no resto do Sahel, a capacidade de resposta do sistema de saúde frente a pressão exercida pela pandemia é globalmente questionada pela insuficiência dos investimentos em infraestruturas, equipamentos e recursos humanos, por problemas de gestão e por uma baixa capilaridade espacial do sistema que limita o acesso da população das áreas periféricas, em regiões rurais e na periferia da capital. $\mathrm{O}$ alto nível de violência registrado em zonas pouco controladas pelo Estado restringe, por sua parte, o acesso as unidades sanitárias (MONIÉ, 2020).

O sistema público de saúde de Burquina Fasso enfrenta vários e complexos desafios. Nos últimos anos, notamos um aumento absoluto dos recursos orçamentários alocados ao setor, ao ponto que $12,6 \%$ do orçamento anual da nação lhe são atualmente alocados. Segundo o Ministério da Saúde, entre 2011 e 2015, esse esforço permitiu investir em infraestruturas e serviços sanitários em todo o território nacional. Graças ao aumento do número de unidades sanitárias de base, que passou de 1.443 para 1.698, o raio de ação espacial teórico de cada unidade teria diminuído de 7,4 quilômetros em 2011 para 6,5 quilômetros em 2015, aumentando sensivelmente o nível médio de acessibilidade potencial da população (SNADDT, 2017). O objetivo das autoridades é alcançar a norma de 5 quilômetros de área de influência recomendada pela OMS mediante o aumento do número de dispensários e maternidades. Investimentos são também alocados na formação e capacitação de recursos humanos. Auditorias visam, por sua parte, a melhorar o planejamento e a gestão multiníveis do sistema (SNADDT, 2017). Mas, apesar dos progressos registrados nos últimos anos estamos ainda aquém do objetivo de $15 \%$ do orçamento aplicado na saúde proclamado na ocasião do encontro da Comissão Econômica dos Estados da África Ocidental (CEDEAO) em Abuja (05/2015).

Além disso, observamos que desde 2008/09 o percentual do PIB dedicado a saúde vem diminuindo. Em 2014, num contexto de elevado crescimento econômico do país, esse percentual voltou para seu patamar de 1995.

\section{Gráfico 1}

Evolução da relação despesas públicas em saúde /PIB

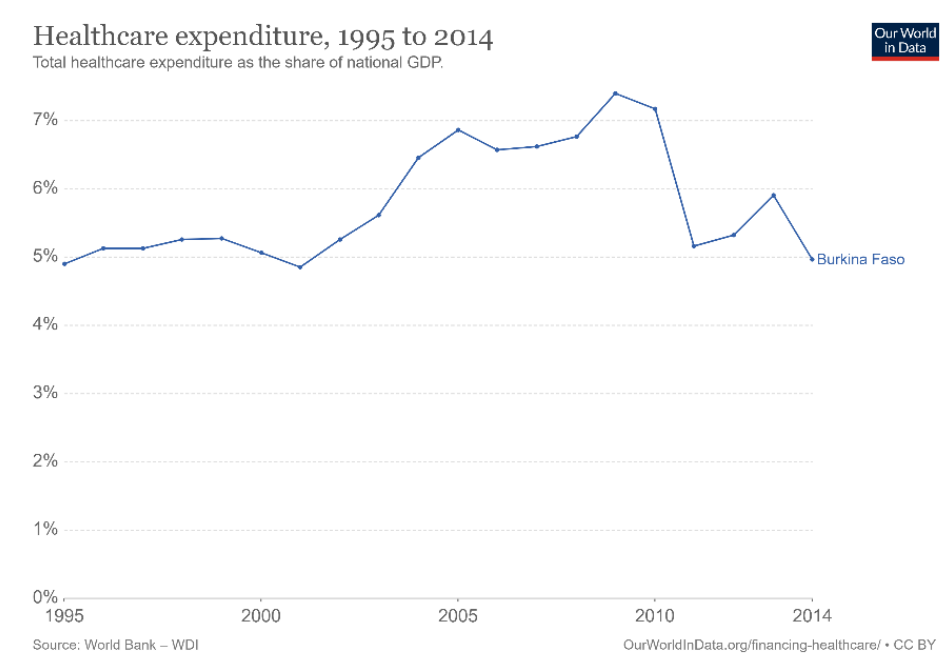

Fonte: Banco Mundial

Frente a multiplicação dos casos de contaminação, o sistema público de saúde tenta se organizar para enfrentar fluxos crescentes de doentes, lidando com fatores críticos 
comuns à maioria dos países africanos. No Centro Hospitalar Universitário (CHU) de Tengandago em Ouagadougou, o "circuito dos doentes" de COVID-19 foi inaugurado no início de abril de 2020 para administrar com fluidez e racionalidade a circulação entre a zona de triagem e os serviços de terapia intensiva (DOUCE, 2020). Apesar da instalação de cerca de 50 leitos suplementares, os riscos de saturação da unidade de referência são considerados elevados. Outro risco é relativo à continuidade do suprimento das unidades de saúde em testes de detecção, material, equipamentos e remédios, enquanto o levado nível de exposição dos profissionais da saúde constitui um motivo de preocupação suplementar num país que conta somente 1 médico por 20.000 habitantes (DOUCE, 2020).

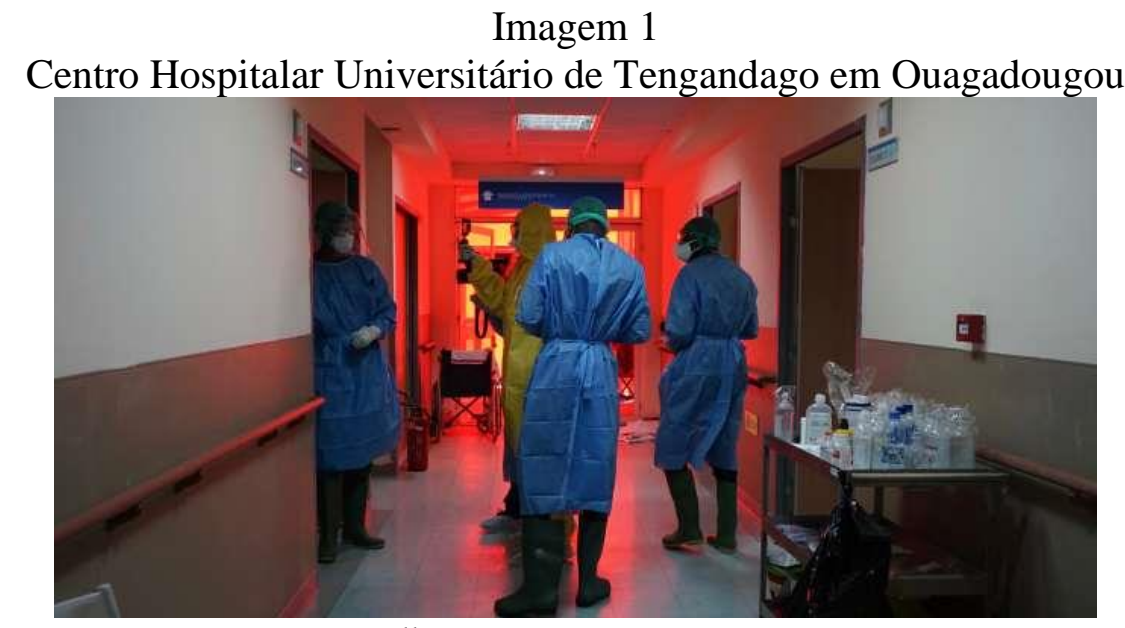

Fonte: Urgence Nouvelle

Políticas, medidas e protocolos de prevenção adotados pelas autoridades

Quando as primeiras infecções foram notificadas na China, a sociedade de Burquina Fasso manifestou imediatamente sua preocupação em consequência da intensificação da mobilidade humana $\mathrm{e}$ das trocas comerciais que seguiu $\mathrm{o}$ reestabelecimento das relações diplomáticas entre os dois países em 2019 (TILOUINE, PEDROLETTI, 2019).

Após o registro oficial dos primeiros casos de contaminação pelo Coronavírus (09 de março de 2020), o governo criou um Comitê Nacional de Riposta e adotou um conjunto de medidas como a promoção de gestos barreira (distanciamento social, higiene pessoal, uso de máscaras, proibição das aglomerações de mais de 50 pessoas), o fechamento das fronteiras aéreas e terrestres, a suspensão das atividades de ensino nas escolas, colégios e universidades, o fechamento dos comércios não essenciais, dos espaços de culto etc. $\mathrm{Ou}$ seja, trata-se, nesta fase, de criar efeitos de barreira entre o território nacional e o exterior e, em microescala, entre os indivíduos no intuito de limitar o processo de difusão espacial da pandemia. 


\section{Imagem 2}

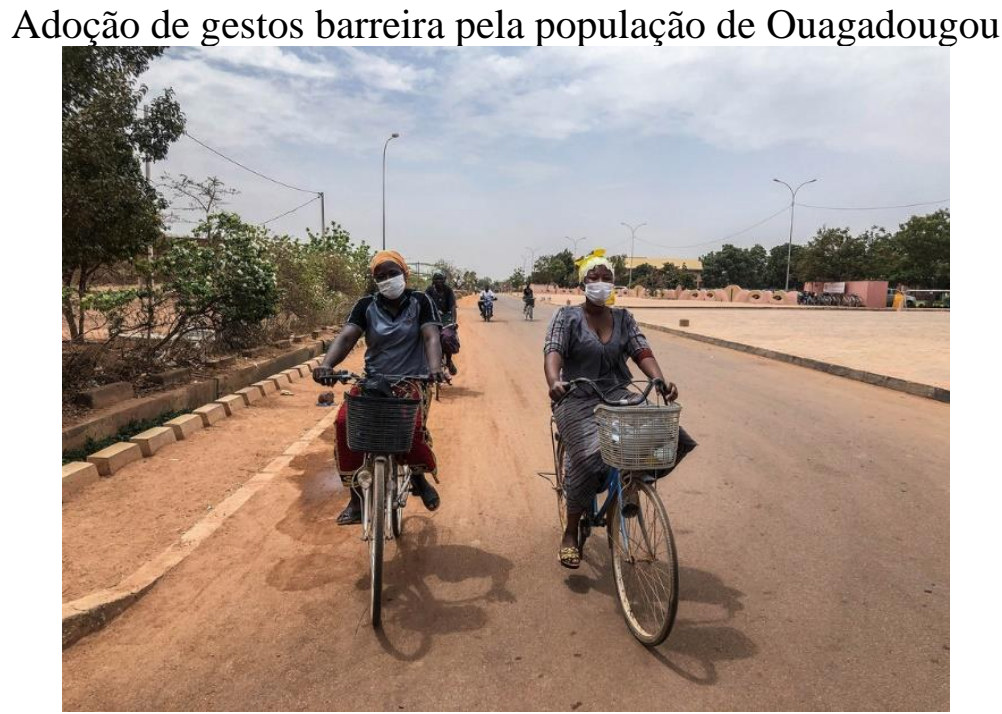

Fonte: Sam Mednick/TNH

Rumores relativos à suposta resistência dos Africanos, em maioria jovens e vivendo em regiões quentes, gerou incialmente certa resistência em relação às medidas de contenção adotadas pelo governo (MONIÉ, 2020). O fato que os primeiros contaminados sejam indivíduos pertencendo a categorias sociais privilegiadas, acostumadas a andar de avião e a frequentar os espaços das elites do país agravou a incredulidade da população frente ao risco pandêmico (LEFASONET, 2020; FAYE, 2020). As lacunas na política de comunicação das autoridades contribuíram, por seu lado, para a disseminação de boatos e fake news na sociedade.

No decorrer do mês de abril, frente ao crescimento do número de casos de pessoas contaminadas e as críticas de profissionais da saúde pública, os protocolos de atendimento nas unidades sanitárias sofreram alterações para conferir mais segurança aos doentes, enfermeiras e médicos. E o governo decidiu também alocar 15 B. de CFA (14 M. de reais) na pesquisa em doenças infecciosas e na produção de remédios.

\section{A adoção de medidas de mitigação dos impactos sociais da pandemia}

As medidas adotadas imediatamente após as primeiras notificações de casos de COVID-19 pelos governos de países vizinhos (Senegal, Níger, Costa do Marfim) geraram uma expectativa que animou debates na sociedade e nas mídias de Burquina Fasso. A questão da mitigação dos impactos sociais suscitou interrogações e questionamentos, num clima marcado pela diminuição da renda de trabalhadores formais pouco qualificados e de trabalhadores dos circuitos inferiores da economia (Santos, 1979).

No dia 02 de abril de 2020, o governo anunciou eixos de ação para garantir a oferta de serviços sanitários e um plano de sustentabilidade orçamentária para adaptar a economia ao novo contexto. Podemos destacar medidas de apoio direto à população (subsídios para pagar as contas de água e energia elétrica, gratuidade da água nas fontes públicas, distribuição de alimentos); de amparo ao setor informal (suspensão do pagamento de aluguel de lojas, de pagamento das contas de água e energia, doação de cestas básicas) e de garantia da segurança alimentar (venda de estoques de alimentos em estabelecimentos credenciados, gestão dos estoques de produtos de base, apoio as atividades de comércio de frutas e legumes, subsídios para a compra de insumos e alimentos para o rebanho) (SIG/BF, 2020). 
Medidas de cunho mais econômico almejam, também, mitigar os efeitos sociais da pandemia: diminuição das taxas e impostos para pequenas e médias empresas; fundo de investimento de 100 bilhões de CFA (9 B. de reais) destinado as empresas e aos atores do setor informal, em particular mulheres em dificuldade etc.

\section{A sociedade de Burkina Fasso frente a pandemia}

A partir de meados de março de 2020, a adoção de medidas preventivas e de contenção territorial, assim como a decretação da quarentena obrigatória em cerca de 40 cidades, geraram debates na sociedade. Mas foi a elevada taxa de letalidade do COVID19 que alimentou dúvidas e críticas na população. No dia 10 de abril, o portal Lefaso.net publicou uma síntese dos resultados de um estudo realizado por um grupo interdisciplinar de pesquisadores em ciências sociais de Universidades de Ouagadougou que entrevistou on line 354 indivíduos sobre sua percepção da pandemia de Coronavírus/COVID-19 (LEFASONET, 2020). O conhecimento da representação da pandemia pela população é legitimado pela necessidade de elaborar campanhas de informação esclarecendo a sociedade da maneira precisa e didática (BOURAIMAN, 2020). Segundo os signatários do texto:

\footnotetext{
As primeiras medidas não trouxeram segurança para as populações pois não eram acompanhadas por medidas sociais e eram consideradas insuficientes diante das situações de risco muito graves geradas pelo coronavírus. Com efeito, muitos acham inadaptado o horário do toque de recolher e perigosa a ausência de medidas para acompanhar as categorias mais pobres da população (LEFASO.NET, 2020)
}

Informados sobre a natureza interpessoal da transmissão do vírus, os indivíduos são dominados por um sentimento de medo que alimenta expectativas e críticas em relação a ação estatal (LEFASONET, 2020). O confinamento rígido é avaliado positivamente pela maioria que teme, no entanto, os impactos socioeconômicos da medida sobre a renda de famílias dependendo na sua maioria de recursos monetários propiciados cotidianamente por atividades informais. Os pesquisadores apontam riscos de revoltas urbanas em caso de forte deterioração das condições de existência dos segmentos mais vulneráveis da população. O anúncio de medidas sociais pelo governo é, por isso, apreendido como uma estratégia de manutenção da paz social no país. As reivindicações expressas pelos entrevistados dizem também respeito ao forte aumento do preço do álcool em gel, das máscaras e dos produtos de limpeza que impacta seu poder aquisitivo (LEFASONET, 2020).

Outro estudo de Paré C. et al. (2020) foca também a avaliação da ação governamental por parte da população. Os pesquisadores, que entrevistaram 1.312 pessoas, mostram que, apesar da percepção diferenciada em função dos níveis de renda e de educação, da ocupação socioprofissional e do "gênero de vida", as principais medidas adotadas pelo governo são globalmente avaliadas positivamente. Mais de $80 \%$ dos entrevistados são, por exemplo, favoráveis ao fechamento dos estabelecimentos de ensino, às campanhas de sensibilização das mídias, à mobilização dos pesquisadores e à proibição do transporte de pessoas. Os gestos barreiras da vida cotidiana foram aprovados pela população, com exceção do respeito de uma distância interpessoal de 1,0 metro, considerada mais problemática por uma ampla maioria dos entrevistados (PARÉ et al., 2020). Em escala intraurbana, a proximidade das pessoas em espaços ainda bastante frequentados, como as feiras livres, pode se revelar problemática nas próximas semanas. 
O relatório evidencia, também, que 53\% dos indivíduos da amostragem consideram que a gestão da pandemia pelas autoridades não é satisfatória.

\section{Tabela 3}

\section{Apreciação das medidas anti-Covid 19}

\begin{tabular}{|l|c|c|c|c|c|c|}
\hline Mesures du gouvemement-BF & Très efficace & Efficace & $\begin{array}{c}\text { Pas dú tout } \\
\text { efficace }\end{array}$ & $\begin{array}{c}\text { Pas } \\
\text { efficace }\end{array}$ & Indiffèrent & Total \\
\hline M1- Mise en quarantaine des villes touchées & $22 \%$ & $46 \%$ & $11 \%$ & $19 \%$ & $1 \%$ & $100 \%$ \\
\hline $\begin{array}{l}\text { M2- Fermeture des écoles /Universités/Centres de } \\
\text { formation }\end{array}$ & $48 \%$ & $43 \%$ & $3 \%$ & $4 \%$ & $1 \%$ & $100 \%$ \\
\hline M3- Couvre-feu de 19h00-5h00 & $22 \%$ & $33 \%$ & $19 \%$ & $24 \%$ & $1 \%$ & $100 \%$ \\
\hline $\begin{array}{l}\text { M4- Interdiction de rassemblement de plus de 50 personnes } \\
\text { s }\end{array}$ & $29 \%$ & $38 \%$ & $9 \%$ & $23 \%$ & $1 \%$ & $100 \%$ \\
\hline M5- Campagnes de sensibilisation dans les médias & $38 \%$ & $52 \%$ & $4 \%$ & $7 \%$ & $0 \%$ & $100 \%$ \\
\hline M6- Arrét des transports de personnes & $43 \%$ & $42 \%$ & $4 \%$ & $10 \%$ & $1 \%$ & $100 \%$ \\
\hline M7- Fermetures de certains marchés & $21 \%$ & $40 \%$ & $11 \%$ & $24 \%$ & $3 \%$ & $100 \%$ \\
\hline M8- Mise à contribution des chercheurs & $48 \%$ & $39 \%$ & $1 \%$ & $9 \%$ & $4 \%$ & $100 \%$ \\
\hline
\end{tabular}

Fonte: Paré C. et al. (2020)

\section{A difusão do Corováriu/Covid 19 em Burquina Fasso: atores, redes e dinâmicas espaciais}

No dia 20 de março de 2020, 11 dias após a primeira notificação de infecção, a distribuição geográfica dos casos de Coronavírus/COVID-19 no território nacional era caracterizada por uma concentração nítida das ocorrências na capital (57 doentes de um total de 64).

Mapa 2

Distribuição geográfica dos casos de Coronavírus/COVID-19 no Burquina Fasso $20 / 03 / 2020$

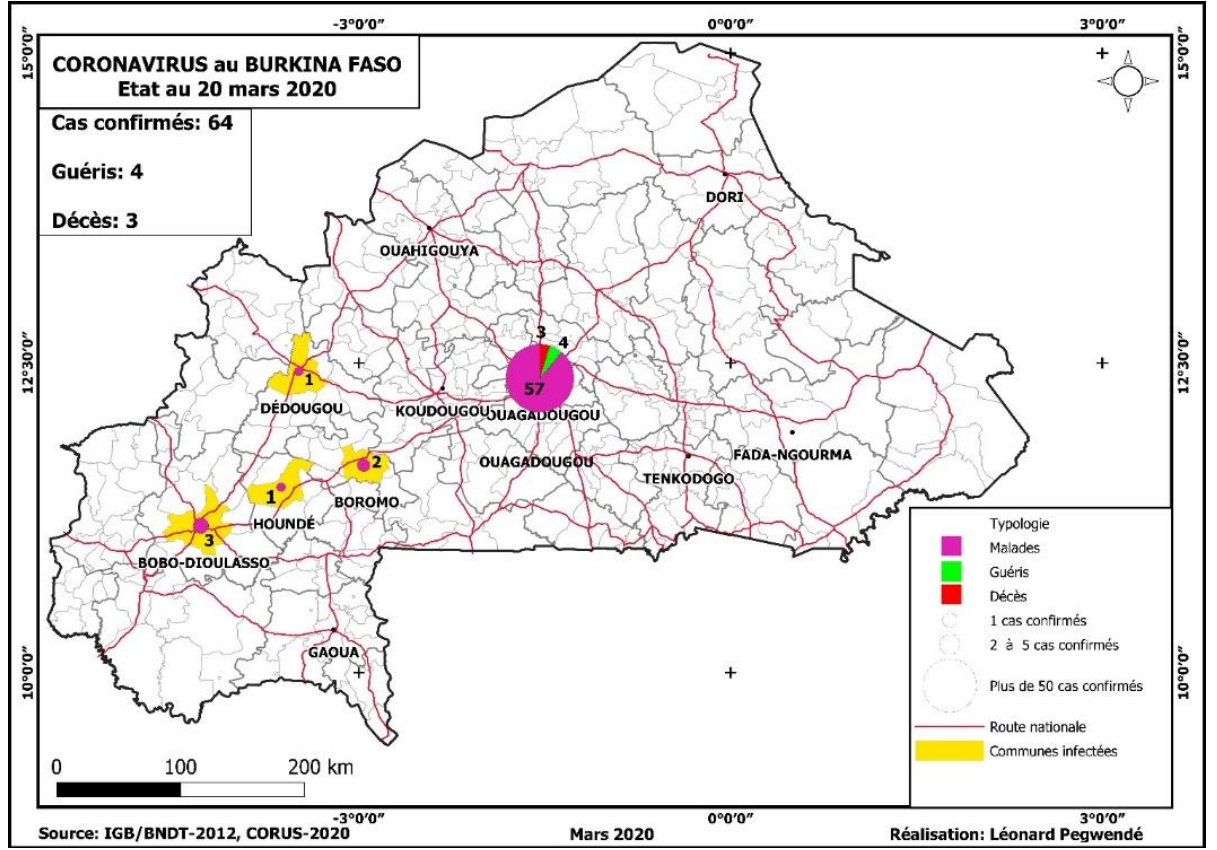

O aeroporto internacional Thomas Sankara de Ouagadougou foi a primeira porta de entrada do Coronavírus em Burquina Fasso. Um casal de pastores que tinha participado de um encontro mundial da igreja evangélica A Porta Aberta Cristão, que reuniu cerca de 2.500 fiéis na cidade francesa de Mulhouse entre os dias 17 e 21 de fevereiro de 2020, 
foi testado positivo ao Coronavírus no dia 09 de março, dias após seu retorno no país. A segunda vítima foi o embaixador da Itália, que após regressar de Roma teria contaminado, direta e indiretamente, dezenas de pessoas nos círculos políticos e diplomáticos de Ouagadougou na ocasião de uma cerimônia da qual participou. Ou seja, conforme ocorreu em diversos países e capitais do Mundo os primeiros doentes eram indivíduos conectados à redes globais, respectivamente religiosas e diplomáticas. Convém observar que, ao exemplo do que foi observado em vários países da região, a plataforma aeroportuária de Paris funcionou como hub de difusão do vírus para a África ocidental (MONIÉ, 2020).

A grande concentração de casos de contaminação na maior aglomeração do país (2,7 milhões de habitantes) decorre essencialmente da combinação de dois fatores de risco. O primeiro relaciona-se com a presença na capital dos segmentos da população mais inseridos no espaço global de fluxos (CASTELLS, 1999): dirigentes locais ou estrangeiros de empresas, executivos, cooperantes, diplomatas, altos funcionários nacionais, estudantes universitários, artistas ou pesquisadores etc. O tráfego aéreo regional (África ocidental) e intercontinental (Europa ocidental e Oriente Médio) potencializa, portanto, a importação do vírus através do transporte aéreo, segundo lógicas que não obedecem ao efeito de contiguidade espacial. Neste momento, a distância é uma variável menos relevante do que a conectividade (MONIÉ, 2020). Foi, portanto, a inserção de Ouagadougou em territórios-redes (VELTZ, 1999; HAESBAERT, 2020) da globalização que criou as condições iniciais de um meio propício ao processo de difusão espacial da pandemia de Coronavírus/COVID-19 (HÄGERSTRAND, 1952). Nesta fase, o baixo nível de importação de casos reflete a inserção periférica de Burquina Fasso na Divisão Internacional do Trabalho (DIT) e nas redes logísticas globais (MONIÉ, 2020).

Após a importação do vírus, uma primeira onda de contágio afetou essencialmente círculos socialmente privilegiados da capital através de reuniões de trabalho, cerimonias e formas de convívio social da vida cotidiana. O efeito de vizinhança é, portanto, fundamental nesta fase de difusão espacial do vírus em escala local. A métrica do contágio muda e a distância passa a se tornar um fator crítico através da co-presença. A adoção de medidas de isolamento social e contenção territorial não é suficiente para romper a dinâmica de difusão do vírus em escala intraurbana segundo uma lógica zonal. O número de habitantes de Ouagadougou oficialmente contaminados passa de 47 para 495 entre os dias 20 de março e 20 de abril de 2020.

A primeira difusão segue um padrão de ondas de continuidades (HÄGERSTRAND, 1952) num ambiente urbano onde a multiplicidade dos atores, das métricas e das variáveis dificulta o levantamento de informações, de dados e a construção de abordagens sistêmicas. Fatores como densidade populacional, nível de desenvolvimento, desigualdades sociais, condições habitacionais, qualidade do sistema de saúde, comportamentos sociais, práticas culturais ou estilo de vida são determinantes na fase do contágio comunitário. O fator distancia adquire então sua plena relevância.

\section{Esquema 1}

Esquema hipotético de difusão por contiguidade espacial

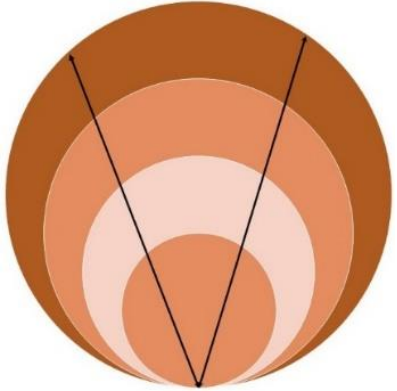


Segundo Wanjiku Kihato e Landau, a informalidade do mercado de trabalho no contexto de um jobless urban growth, a precariedade das condições sanitárias nos loteamentos e favelas e a distribuição muito desigual dos recursos urbanos desenham um quadro de injustiça espacial que expõe a vulnerabilidade dos segmentos mais pobres da população diante da pandemia (WANJIKU KIHATO, LANDAU, 2020). Diante deste quadro de injustiça espacial, as pesquisadoras sul-africanas contestam o recurso à força por parte das autoridades e advogam em prol de um contrato social inclusivo e suscetível de mitigar os efeitos da pandemia (WANJIKU KIHATO, LANDAU, 2020).

Paralelamente, Ouagadougou começa a se posicionar como epicentro nacional da pandemia, graças a um meio doravante favorável a difusão multiescalar do vírus (HÄGERSTRAND, 1952). Devemos então analisar esse processo segundo duas escalas de contágio ilustradas pelo mapa 3.

\section{Mapa 3}

Distribuição geográfica e difusão espacial do Coronavírus/COVID-19 em Burquina Fasso

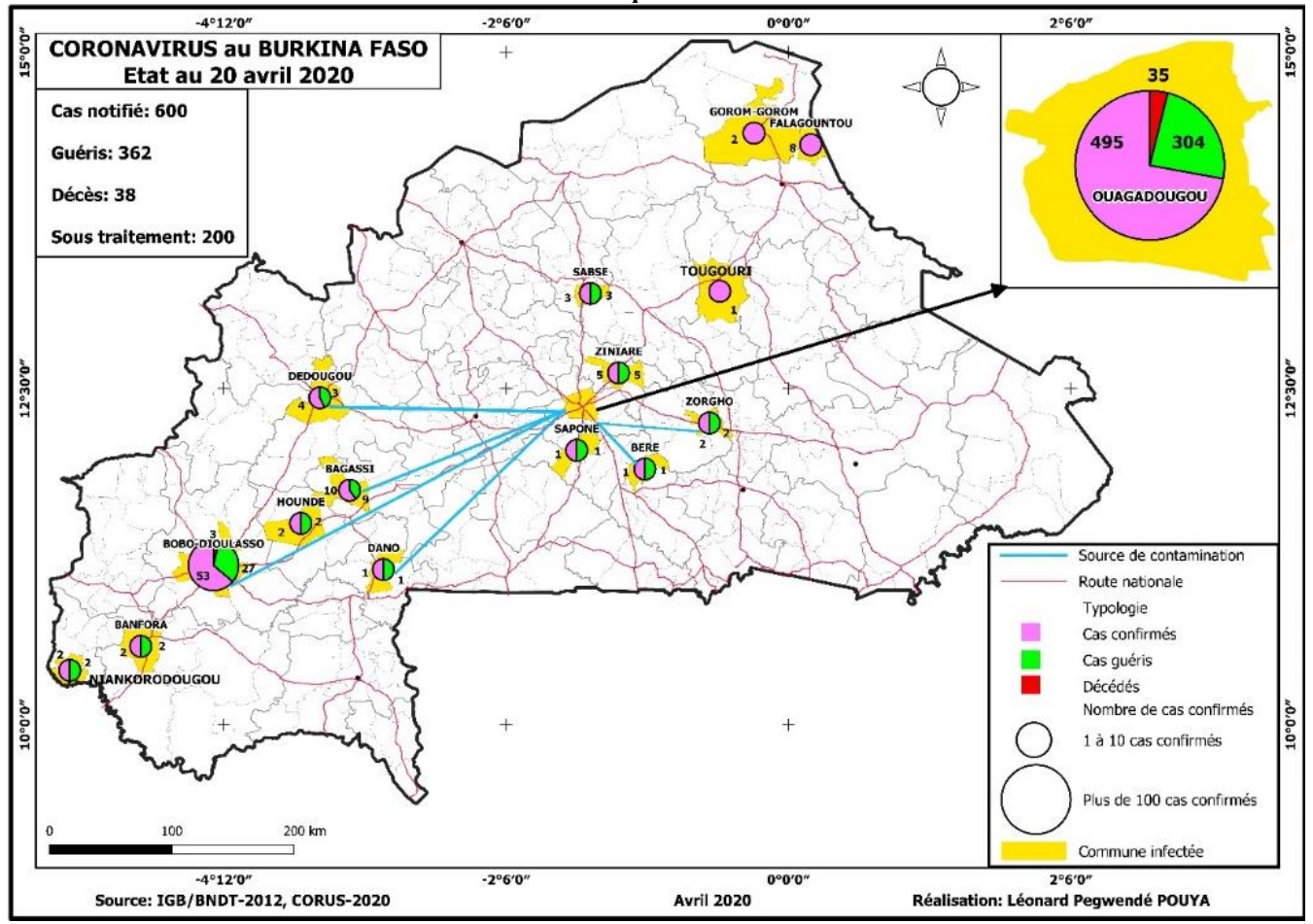

Em decorrência de sua centralidade multinível, Ouagadougou desempenha um papel de lugar central e, consequentemente, de $h u b$ de difusão do vírus para cidades de pequeno porte localizadas num raio de influência de aproximadamente 100 quilômetros (Ziniare, Sapone, Sarse, Zorgho). As interações espaciais são, nesta escala meso regional, estruturadas por fluxos de consumidores em busca de bens e serviços não disponíveis nos pequenos centros urbanos e espaços rurais (CHRISTALLER, 1966). Os fluxos do abastecimento da capital em gêneros alimentícios a partir da hinterlândia regional alimentam, por seu lado, uma intensa vida de relações propicia a difusão espacial da pandemia. Estamos, neste caso, diante de métricas de médio alcance geográfico apresentando uma nítida dimensão zonal. 


\section{Esquema 2}

Esquema de difusão hipotética. Padrão hierárquico

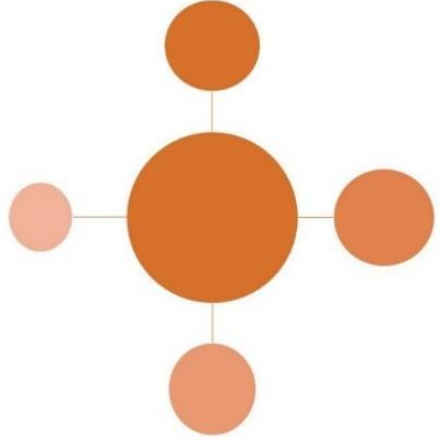

A capital Ouagadougou é também o epicentro da transmissão do vírus em escala nacional. A difusão espacial do vírus segue um padrão comum a muitos fenômenos de contágio epidemiológico. Os eixos de circulação terrestres formam vetores maiores de circulação de pessoas contaminadas, segundo um padrão multinível de tipo hub and spokes. O mapa 3 evidencia que o maior eixo viário de Burkina Fasso, conectando Ouagadougou a Niankorodougou, cidade fronteiriça do sudoeste do país, constituiu o principal vetor de difusão do Coronavírus para o interior. A intensidade das trocas comerciais entre a capital política e Bobo-Dioulasso, capital econômica do país, confere sua força de impulso ao processo de difusão espacial (HÄGERSTRAND, 1952).

\section{Esquema 2}

Esquema de difusão hipotética. Padrão de tipo hub and spokes

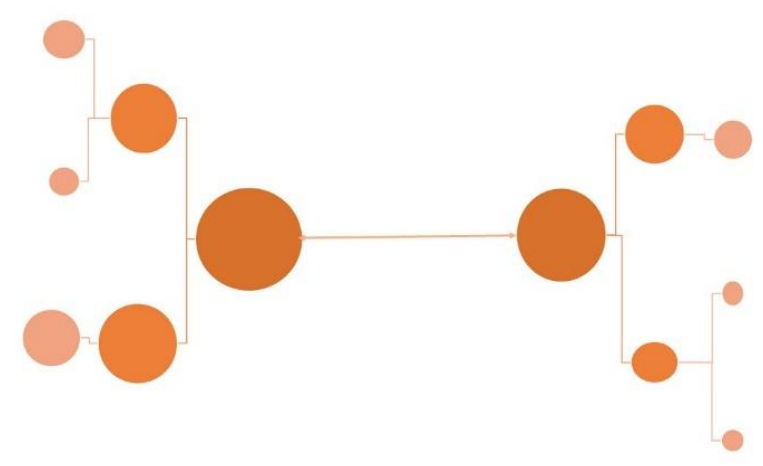

Bobo-Dioulasso, segunda cidade do país (tabela 4) e importante centro econômico (indústria têxtil), é um lugar central na região ocidental de Burquina Fasso funcionando como centro de prestação de serviços e negócio comércio de produtos agrícolas, em particular de algodão. A aglomeração parece desempenhar um papel de $h u b$ no processo de propagação do vírus, entre um nó maior (Ouagadougou) relativamente distante (350 quilômetros) e um conjunto de centros urbanos de pequeno porte de sua hinterlândia regional. 
Tabela 4

Hierarquia urbana e notificações de casos do Coronavírus/COVID-19

(dados 20/04)

\begin{tabular}{|c|l|c|c|c|}
\hline \multicolumn{2}{|c|}{ Cidade } & População & $\begin{array}{c}\text { Casos } \\
\text { notificados }\end{array}$ & Óbitos \\
\hline & \multicolumn{1}{|c|}{ Cidana } & 495 & 35 \\
\hline 1 & Ouagadougou & 2684052 & 53 & 3 \\
\hline 3 & Bobo-Dioulasso & 887778 & 14 & 0 \\
\hline 4 & Borom-Gorom & 171829 & 2 & 0 \\
\hline 5 & Dédougou & 169879 & 5 & 0 \\
\hline 6 & Houndé & 129200 & 2 & 0 \\
\hline 7 & Tougouri & 122804 & 1 & 0 \\
\hline 8 & Ziniaré & 114117 & 5 & 0 \\
\hline 9 & Zorgho & 90766 & 2 & 0 \\
\hline 10 & Dano & 68515 & 1 & 0 \\
\hline 11 & Niankorodougou & 57725 & 2 & 0 \\
\hline 12 & Saponé & 51566 & 1 & 0 \\
\hline 13 & Béré & 42913 & 10 & 0 \\
\hline 14 & Boromo & 41192 & 3 & 0 \\
\hline 15 & Sabcé & 33642 & 3 & \\
\hline 16 & Falangoutou & 27870 & & 0 \\
\hline & & & & \\
\hline
\end{tabular}

Fonte: INSD (Projecção 2020) 2020, CORUS, 20 abril 2020

Observamos, enfim, um elevado número de casos de contaminação em cidades abrigando sítios extrativistas auríferos de grande porte como Houndé (Houndé Gold Operations SA), Sindou (Mina de Niankorodougou), Kongoussi (Bissa Gold SA - BissaBouly), Gorom-Gorom (Iamgold Essakane SA - Essakane).

\section{Imagem 3}

Sítio de extração aurífera da Houndé Gold Operations AS - Houndé

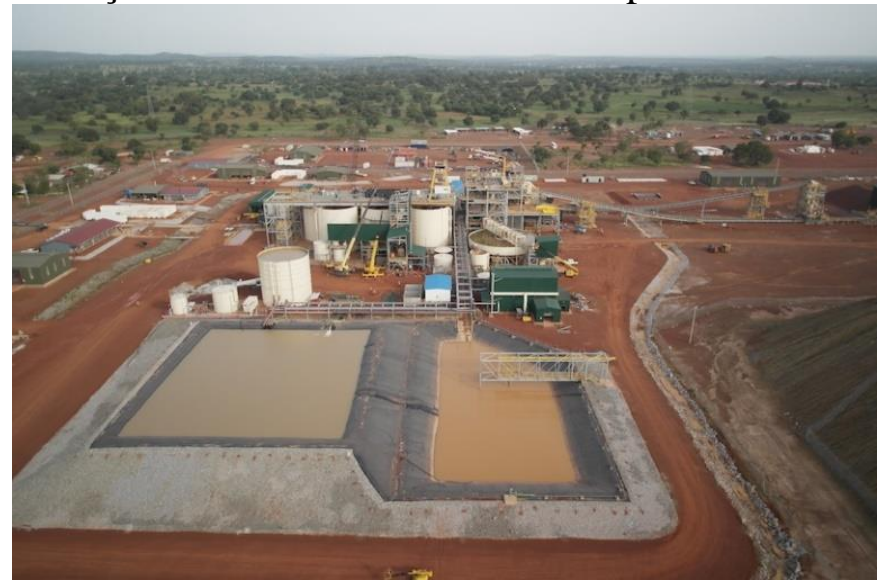

Fonte: https://www.endeavourmining.com/

A situação sanitária dos sítios extrativistas de grande porte revela-se bastante peculiar num contexto pandêmico: 
as multinacionais africanas e estrangeiras ao continente estruturam suas operações em sítios produtivos e vetores de transporte eficientemente conectados às redes dos mercados de commodities. Os enclaves produtivos [...] são expostos de maneira paradoxal a pandemia: os trabalhadores qualificados estrangeiros circulam nos territórios redes do arquipélago econômico mundial, sendo, portanto, sujeitos a contaminação nas plataformas aeroportuárias mundiais. Por sua parte, a vida no interior do enclave é estruturalmente confinada em relação à um fora apreendido com um espaço de riscos para os corpos protegidos. Os enclaves, territórios-zona que têm a capacidade de modular suas interações com os espaços contíguos em função de riscos ambientais, sociais e geopolíticos, devem administrar o dilema de sua inserção nos circuitos logísticos mundiais e de seu abastecimento em produtos básicos, sendo eles importados ou locais (Monié, 2020).

No que diz respeito as modalidades de difusão para as regiões mineiras do Nordeste de Burquina Fasso, podemos emitir a hipótese que trabalhadores contaminados "exportaram" o Coronavírus via conexões aéreas que ligam Ougadougou aos sítios de extração de ouro. A difusão do vírus por transporte aéreo gera um efeito túnel na cadeia de contágio entre os pontos de origem e destino.

A situação sanitária em centenas de garimpos informais, onde trabalham aproximadamente 1 milhão de garimpeiros, permanece desconhecida até o presente momento. No entanto, sabemos que existe uma multiplicidade de fatores críticos favoráveis a uma difusão espacial de tipo comunitário do Coronavírus: elevada densidade populacional nas minas e nos acampamentos, pré-existência de patologias como malária ou silicose, estruturas sanitárias locais extremamente precárias, população flutuante, ausência de proteção social etc. (MONIÉ 2020; YONLIHINZA, 2017). As condições são, portanto, reunidas para a expansão do contágio nestas regiões periféricas conectadas ao mercado mundial do ouro pelo trabalho de centenas de milhares de indivíduos invisíveis.

Imagem 4
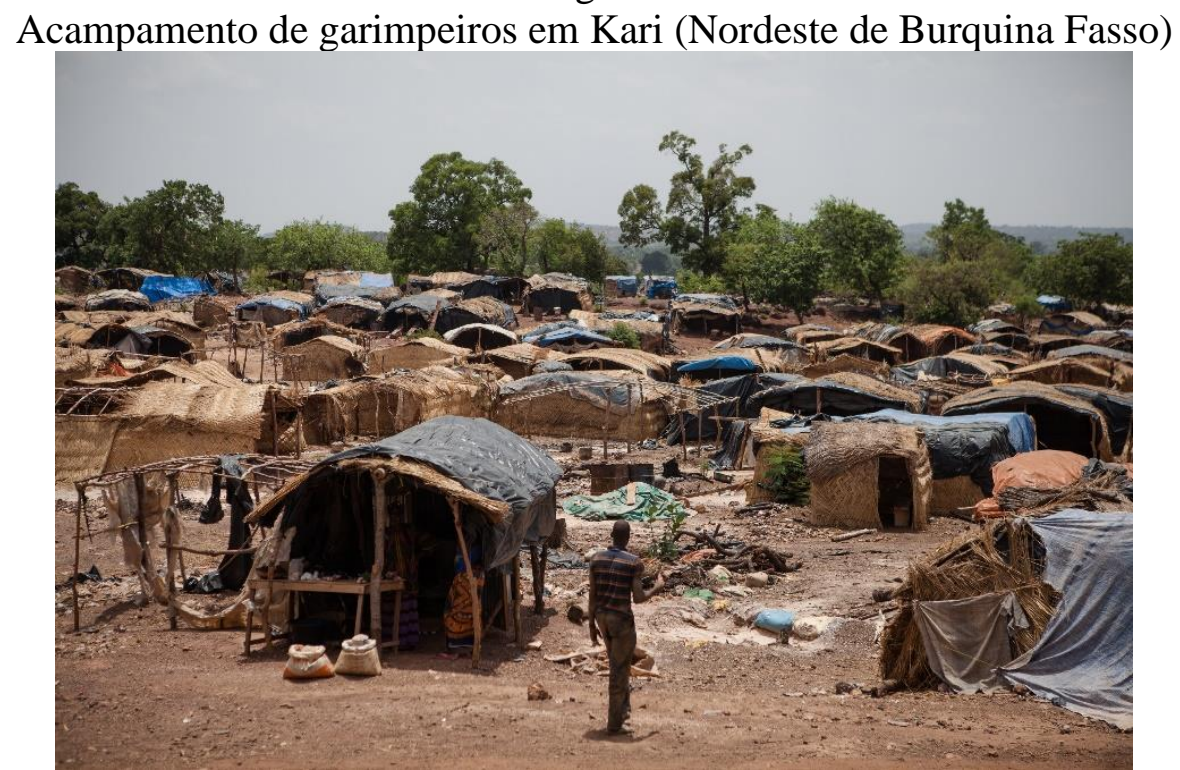

Foto: Sophie Garcia/Hans Lucas

\section{Primeiras considerações...}

A ausência de distanciamento temporal em relação ao objeto de estudo, a precariedade da base de dados sobre a situação sanitária e o caráter muito dinâmico do 
evento aqui analisado dificultam a apreensão de sua natureza, da realidade precisa do contágio nas sociedades da África subsaariana e de Burquina Fasso, do ritmo da propagação do vírus e de seus primeiros impactos socioeconômicos. Se algumas variáveis de análise da pandemia se revelam pertinentes na escala continental (estado dos sistemas públicos de saúde, importância do setor informal, desigualdades sociais e regionais, nível de desenvolvimento humano etc.), a diversidade das formações socioespaciais africanas estimula a privilegiar abordagens multiníveis e multiescalares das manifestações e dos efeitos da pandemia de Coronavírus/COVID-19. A evolução muito rápida da situação sanitária conforta a opção em prol de uma abordagem dinâmica do fenômeno em escalas regionais e/ou nacionais. No caso específico de Burquina Fasso, estamos diante de uma situação sanitária caracterizada por elevadas taxas de contágio pelo Coronavírus e de letalidade do COVID-19 que constituem motivos de preocupação na sociedade. As autoridades adotaram uma série de medidas de contenção territorial, distanciamento social, mitigação dos impactos econômicos e sociais da pandemia cuja eficiência é de difícil previsão. A capacidade de frear a dinâmica de expansão do contágio, de enfrentar pressões crescentes sobre o sistema de saúde e de garantir a sobrevivência das categorias mais vulneráveis da população definirá o ritmo da propagação do vírus e a e letalidade da doença nos segundo e terceiro trimestre de 2020.

A geografia da pandemia abordada com base no estudo da dinâmica de difusão do vírus no território nacional evidencia tendências relevantes. A fase de "importação" confirma que as grandes plataformas aeroportuárias globais que organizam a malha viária mundial desempenharam um papel fundamental. Os aeroportos de Paris constituíram, assim, o principal nó de transmissão para as capitais da África ocidental, como Ouagadougou. Da mesma maneira, a propagação do vírus entre as elites políticas, diplomáticas e econômicas ilustra a inserção diferenciada nos territórios-rede do espaço global de fluxos, num quadro de desigualdades sociais exacerbadas.

$\mathrm{Na}$ fase da contaminação comunitária, a teoria da difusão espacial elaborada por Torsten Hägerstrand e algumas das noções tradicionalmente mobilizadas pela análise espacial conferem recursos analíticos relevantes para analisar de que maneira se articulam as métricas do contágio, as dimensões zonais e territoriais da propagação do vírus, o papel dos diferentes nós e vetores de transmissão etc. No que diz respeito à África subsaariana em geral e a Burquina Fasso em particular, podemos destacar a relevância das interações espaciais de curto e médio alcance geográfico relacionadas ao abastecimento alimentar das cidades, que depende concomitantemente das importações de alimentos de base e da drenagem de gêneros alimentícios na hinterlândia local/regional. Observamos também a especificidade da difusão espacial da pandemia em espaços econômicos nacionais fortemente estruturados pelo extrativismo mineral. O desenvolvimento da economia aurífera foi acompanhado por uma multiplicação e uma dispersão dos sítios de extração, formais e informais, no território nacional. Os focos de contágio em minas de ouro ilustram as faces paradoxais e perversas da inserção da África subsaariana na globalização. Os mecanismos, vetores e métricas da difusão do vírus nestes espaços são ilustrativos de uma inserção desigual nos territórios-redes globais, da dualidade dos circuitos espaciais de produção e da invizibilização dos corpos dos mineiros artesanais mais expostos à pandemia nas periferias da periferia. 


\section{Referências bibliográficas}

AFRICAN UNION. Impact of the Coronavirus Covid-19 on the African Economy. Adis Abeba: African Union, 2020.

AMREF.HEALTH AFRICA. Amref COVID-19 Africa Information Centre. https://amref.org/coronavirus/?fbclid=IwAR0PyW_2ZX_DSCBLoe-

SgVq9gpn4YDapFkQ6qhWIBzSNt79oNmN8oCf6s2o

BOURAIMAN, Zongo et al., 2020. La maladie à Corona virus au Burkina Faso: Perceptions et attentes de la population. LeFaso.net, Ouagadougou, 10/04/2020. https://lefaso.net/spip.php?article96118

BURKINA FASO: Plan National de Développement économique et social du Burkina Faso (PNDES) 2016-2020, Ouagadougou, (s/d).

BURKINA FASO (b): Schéma national d'aménagement et de développement durable du 2040. Ouagadougou, 166 p., 2017.

CASTELLS, Manuel. A sociedade em rede. São Paulo: Paz e Terra, 1999.

CHRISTALLER, Walter. Central places in Southern Germany. Englewood Cliffs: Prentice-Hall, 1966.

DAUDÉ, Éric, ELIOT, Emmanuel. Diffusion des épidémies et complexités géographiques. Espace, populations, sociétés, Paris, n²-3, pp.403-416, 2006.

DOUCE, Sophie. Au Burkina Faso, avec les «combattants» du CHU de Tengandogo, en guerre contre le Covid-19. Le Monde Afrique, Paris, 20.04.2020.

FAYE, Ousmane. Coronavirus: «Ne nous reposons pas sur l'idée que l'Afrique serait préservée par la jeunesse de sa population». Le Monde Afrique, Paris, 30.03.2020.

HÄGERSTRAND, Torsten. The propagation of innovation waves. Series B, Human geography, 4, London: Royal University of Lund, Dept. of Geography, 1952

HARVEY, David. Social Justice and the City. Baltimore: The Johns Hopkins University Press, 1973.

HARVEY, David. Condição pós-moderna. São Paulo: Loyola, 1989.

HAESBAERT, Rogério: Entre a contenção e o confinamento dos corpos-território: reflexões geográficas em tempos de pandemia (I) e (II). AGB-Campinas, 24.03.2020. Disponível : http://agbcampinas.com.br/site/2020/rogerio-haesbaert-desterritorializacaosem-limites-reflexoes-geograficas-em-tempos-de-pandemia-i/

INSTITUT NATIONAL DE LA STATISTIQUE ET DE LA DEMOGRAPHIE: Projections démographiques des Communes du Burkina Faso de 2007 à 2020, Mars 2017 
LÉVY, Jacques. Os Novos Espaços da Mobilidade. GEOgraphia, Niterói, vol. 3, nº6, 2001.

PARÉ Cyriaque, Drabo; KABRE, Sounkalo; KABRE, Moumouni; COULIBALY Djamila; SONDO Mariam. Perception des mesures anti-Covid 19 au Burkina Faso. Ouagadougou, rapport d'enquête, 2020, 20 p.

https://lefaso.net/IMG/pdf/perception_des_mesures_anti-covid-19_au_burkina_faso.pdf

LE FASO.NET. La maladie à Corona virus au Burkina Faso: Perceptions et attentes de la $\begin{array}{llll}\text { population. Le } & \text { Faso.net, } & \text { Ouagadougou, } & \text { 10.04.2020. }\end{array}$ https://lefaso.net/spip.php?article96118

LÉVY, Jacques; LUSSAULT, Michel (ed.). Dictionnaire de la géographie et de l'espace des sociétés. Paris: Belin, 2003.

MASCARENHAS DE JESUS, Gilmar. Considerações teórico-metodológicas sobre a difusão do futebol. Scripta Nova. Revista Electrónica de Geografía y Ciencias Sociales, Barcelona, Vol. 23, No 69, 2000.

MAHRH (Ministère de l'agriculture, de l'hydraulique et des ressources halieutiques): Rapport statistiques annuels. Ouagadougou, MARHRH, 152 p., 2014.

MINISTERE DE LA SANTÉ: Rapport de situation sur l'épidémie de la maladie à Coronavirus (COVID-19) au Burkina Faso; CORUS, 21 avril 2020.

MONIÉ, Frédéric. A África subsaariana diante da pandemia de Coronavírus/COVID-19: difusão espacial, impactos e desafios. Espaço e Economia, Rio de Janeiro, nº18, 2020.

URL: http://journals.openedition.org/espacoeconomia/13629

ONYIEGO, Mike. How to spread of coronavirus is testing Africa. BBC News, Londres, 11.04.2020.

RAFFESTIN, Claude. La diffusion. In BAILLY, Antoine. Les concepts de la géographie humaine. Paris: Masson, pp189-193, 1994.

SANTOS, Milton. Economia espacial: críticas e alternativas. São Paulo: Hucitec, série Economia \& Planejamento, 1978.

SANTOS, Milton. O espaço dividido: os dois circuitos da economia urbana dos países subdesenvolvidos. Rio de Janeiro: Francisco Alves, 1979.

SAINT-JULIEN, Thérèse (s/d). La diffusion spatiale. Article 11, Hypergeo. https://www.hypergeo.eu/spip.php?article11

SERVICE D'INFORMATION DU BURKINA (SIG). https://web.facebook.com/sigbf $226 /$ ? tn $=\% 2 \mathrm{Cd}<-$ R\&eid=ARB06vdR6j99EucfNufa_f1FtvIhhF15PGLJd3mbgi5qt8krPG7yKDEk4nlF6Y Z8VZGoXNfJ-SUCQxUq 
TILOUINE, Joan; PEDROLETTI, Brice. Le Burkina Fasso à l’heure chinoise. Le Monde, Paris, 13.09.2019.

VELTZ, Pierre. Mundialización, ciudades y territorios. Barcelona: Ariel, 1999.

WANJIKU KIHATO, Caroline; LANDAU, Loren B. Coercion or the social contract? COVID 19 and spatial (in)justice in African cities. City \& Society. posto on line em 28.04.2020. doi:10.1111/ciso.12265

YONLIHINZA, Issa Abdou. Lorsque l'orpaillage pousse à l'exode depuis le cœur du Sahel. The Conversation, Paris, 14.05.2017. 